Article

\title{
Reproducible Molecularly Imprinted Piezoelectric Sensor for Accurate and Sensitive Detection of Ractopamine in Swine and Feed Products
}

\author{
Mingfei Pan, Rui Li, Leling Xu, Jingying Yang, Xiaoyuan Cui and Shuo Wang * \\ Key Laboratory of Food Nutrition and Safety, Ministry of Education of China, Tianjin University of Science \\ and Technology, Tianjin 300457, China; panmf2012@tust.edu.cn (M.P.); singutosleep@126.com (R.L.); \\ apple2ringo@126.com (L.X.); Yangjy0823@126.com (J.Y.); XY.Cui@163.com (X.C.) \\ * Correspondence: s.wang@tust.edu.cn; Tel.: +86-22-6091-2493
}

Received: 14 May 2018; Accepted: 6 June 2018; Published: 7 June 2018

\begin{abstract}
This paper describes the development of a reproducible molecularly imprinted piezoelectric sensor for the accurate and sensitive detection of ractopamine (RAC) in swine and feed products. The synthesized molecularly imprinted polymer (MIP) was directly immobilized on the surface of a quartz crystal microbalance (QCM) Au chip as the recognition element. The experimental parameters in the fabrication, measurement and regeneration process were evaluated in detail to produce an MIP-based piezoelectric sensor with high sensing capability. The developed piezoelectric sensor was verified to perform favorably in the RAC analysis of swine and feed products, with acceptable accuracy (recovery: 75.9-93.3\%), precision [relative standard deviation $(\mathrm{n}=3): 2.3-6.4 \%$ ], and sensitivity [limit of detection: $0.46 \mathrm{ng} \mathrm{g}^{-1}$ (swine) and $0.38 \mathrm{ng} \mathrm{g}^{-1}$ (feed)]. This portable MIP-based chip for the piezoelectric sensing of RAC could be reused for at least 30 cycles and easily stored for a long time. These results demonstrated that the developed MIP-based piezoelectric sensor presents an accurate, sensitive and cost-effective method for the quantitative detection of RAC in complex samples. This research offers a promising strategy for the development of novel effective devices used for use in food safety analysis.
\end{abstract}

Keywords: ractopamine; molecularly imprinted piezoelectric sensor; swine and feed samples; quantitative detection

\section{Introduction}

Ractopamine (RAC) is an artificially synthesized $\beta$-adrenergic agonist, which was originally used as a bronchial dilating agent for the treatment of pulmonary disease and asthma [1,2]. However, in the farming industry, RAC is also illegally applied as a nutrient repartitioning agent to increase muscle and reduce fat accumulation [3-5]. It has been proven that RAC can be retained in animals and subsequently enters the human body through the food chain, causing cumulative toxicity. Thus, when the accumulated RAC dose exceeds a certain level, toxic reactions, such as triggering muscle tremor, tachycardia, and muscle pain, may occur [6-8]. To avoid the potential risk of RAC to human health, many countries (including the USA, China and the European Union) and organizations have set strict regulations for RAC and other $\beta$-adrenergic agonists, with zero tolerance in animal feed or processing $[9,10]$. However, RAC is still frequently detected in swine and feed products. Therefore, the development of an effective method for RAC determination to control the amount of RAC in complex samples, especially the swine and feed products, is necessary for the assurance of consumer health [11].

Currently, RAC is commonly determined via high performance liquid chromatography (HPLC) [12,13], liquid chromatography/gas chromatography-tandem mass spectrometry 
(LC/GC-MS) [14-16], enzyme-linked/fluorescence immunoassay [17], and biosensor analysis [18-21]. Among these, instrumental analysis based on the principles of chromatography and mass spectroscopy is still the main method for RAC detection. These methods are effective and reliable and can detect the presence of the target analyte (RAC) at trace levels in various food samples after a relatively simple pre-treatment process. Molecularly imprinted polymers (MIPs), also known as artificial antibodies, are synthetic materials that can specifically and selectively recognize the target analyte from various samples in a relatively harsh environment [22-24]. Over the past ten years, more in-depth studies on MIP synthesis and its applications have been carried out in the fields of drug delivery, food science, environmental monitoring, and medical testing. This has led to significant progress in the area with good potential for future application [25]. Due to their selective binding affinity, one of the most valuable applications of MIP is their use as solid phase extraction (SPE) sorbents for the purification and enrichment of trace substances present in complex matrices [26,27]. To date, various target analytes, such as proteins, carbohydrates, and small molecules, can be enriched as MIP binding targets. In our previous study, we prepared an RAC imprinted material with good capability. This material was further applied as an enrichment sorbent for the determination of trace RAC in pork samples using on-line solid-phase extraction coupled with HPLC. Another remarkable MIP application was its use as a recognition element in chemical sensors with different types of signals (fluorescence, impedance, current and potential signals). These sensors were stable and selective in harsh environments with low interference [28-30]. However, the high cross-linking degree of molecularly imprinted systems is not conducive to the transmission of electrons and photon. This has led to the reduction in sensitivity and accuracy for the detection of trace target analytes by molecularly imprinted electrochemical and photochemical sensors. Molecularly imprinted piezoelectric sensors that monitor the mass signal combine the merits of molecular imprinting and piezoelectric sensing techniques. This technique displays unparalleled advantages in the identification of signal conversion and detection sensitivity and can realize the real-time and portable analysis of different analytes [31-33]. Quartz crystal microbalances (QCM) are widely used as piezoelectric sensors and can effectively reflect the amount of target analyte bound on the surface of a chip by monitoring the change in the resonant frequency of the quartz crystal [34,35]. Recent years have seen interesting studies on the application of molecularly imprinted QCM sensors for the qualitative and quantitative analyses of different analytes in various fields [36-39].

In this study, a molecularly imprinted piezoelectric sensor was constructed by directly modifying an MIP material with good recognition ability toward RAC onto the surface of a QCM chip. The sensor was further applied to detect trace RAC in swine and feed products (Scheme 1). The proposed piezoelectric sensor afforded consistent detection results via a typical HPLC-MS/MS method with a correlation coefficient $\left(\mathrm{r}^{2}\right)$ of 0.9611 , good accuracy (recovery: 75.9-93.3\%), acceptable precision [relative standard deviation ( $\mathrm{n}=3$ ): $2.3-6.4 \%$ ], and high sensitivity [detection limit: $0.46 \mathrm{ng} \mathrm{g}^{-1}$ (swine) and $0.38 \mathrm{ng} \mathrm{g}^{-1}$ (feed)] in the selected samples spiked with the same levels of RAC. Furthermore, this MIP-based piezoelectric sensor exhibited several advantages such as low-cost, a short detection period, and good reproducibility. Thus, this sensor shows good potential for application as an effective device for the accurate, sensitive and cost-effective detection of RAC. This study has provided an interesting combination of molecular imprinting and piezoelectric sensing techniques as well as a new strategy for the determination of trace amounts of harmful substances in complex samples. 


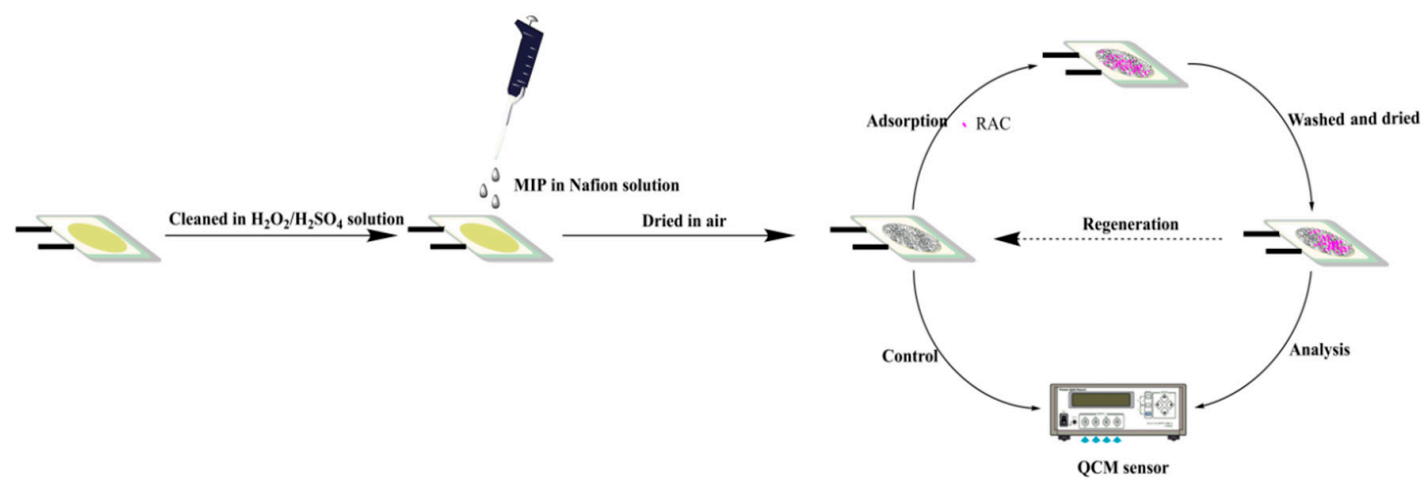

Scheme 1. Schematic diagram of the MIP piezoelectric chip for RAC detection.

\section{Materials and Methods}

\subsection{Reagents and Materials}

The standard product of RAC ( $\geq 99.0 \%)$ and its analogues including isoproterenol, isoxsuprine and terbutaline ( $\geq 99.0 \%$; Figure 1) were purchased from Sigma-Aldrich (St. Louis, MO, USA). The silane reagents 3-aminopropyltriethoxysilane (APTES) and tetraethoxysilane (TEOS) acquired from Hubei Wuhan University Silicone New Material Co. Ltd. (Wuhan, China) were used as the functional monomer and cross-linker for MIP synthesis, respectively. A Nafion ${ }^{\circledR}$ perfluorinated resin solution [5 wt \% in the solution of low aliphatic alcohol (55\%) and water (45\%), Sigma-Aldrich (St. Louis, MO, USA)] was employed for MIP immobilization on the piezoelectric chip surface. Doubly deionized water $(18.2 \mathrm{M} \Omega \mathrm{cm})$ produced by a Water Pro water system (Labconco, Kansas City, MO, USA) was used throughout the whole study. All other chemicals and reagents such as methanol, acetic acid, $\mathrm{HCl}, \mathrm{NH}_{3} \cdot \mathrm{H}_{2} \mathrm{O}$ and phosphates were at least of analytical grade and purchased from Tianjin Chemical Reagent Factory (Tianjin, China).<smiles>CC(CCc1ccc(O)cc1)NCC(O)c1ccc(O)cc1</smiles>

RAC<smiles>CC(COc1ccccc1)NC(C)C(O)c1ccc(O)cc1</smiles>

Isoxsuprine<smiles>CC(Cl)N=CC(O)c1ccc(O)c(O)c1</smiles>

Isoproterenol<smiles>CC(C)(C)NCC(O)c1cc(O)cc(O)c1</smiles>

Terbutaline

Figure 1. Chemical structure of RAC, isoproterenol, terbutaline and isoxsuprine.

The individual stock solutions for all the analytes (RAC, isoproterenol, isoxsuprine, terbutaline) at a concentration of $100.0 \mathrm{mg} \mathrm{L}^{-1}$ were initially prepared by dissolving $10.0 \mathrm{mg}$ standard product into methanol and subsequently stored at $4{ }^{\circ} \mathrm{C}$ in the dark. The corresponding working solutions were produced by diluting the stock solutions with deionized water. The tested swine and feed products were purchased from a local supermarket (Tianjin, China) and confirmed to be free of RAC by HPLC-MS/MS analysis. 


\subsection{Instrumentation}

A quartz crystal microbalance (QCM 922) from Princeton Applied Research (Seattle, WA, USA) was applied for monitoring the shift in oscillation frequency $(\Delta f, \mathrm{~Hz})$ on an overtone polished $9.0 \mathrm{M}$ $\mathrm{Hz}$ AT-cut quartz crystal with Au electrodes on both sides $\left(3000 \AA\right.$, area: $\left.0.196 \mathrm{~cm}^{2}\right)$. A flowing cell $\left(\mathrm{CL}_{6}\right)$ with silicone tubing and a syringe inserted into the mini-fitting were applied to allow the tested solutions to flow over the modified crystal electrode surface. A peristaltic pump (Biosensing Instrument Inc., Tempe, AZ, USA) which could accurately control the liquid flow rate at the range

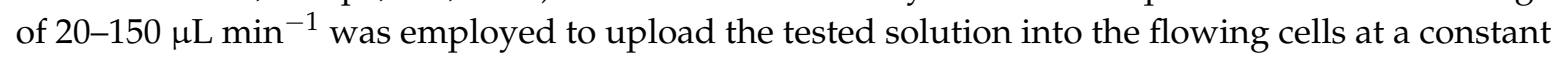
rate. A vortex machine (General Electric Company, Boston, MA, USA) and a solid-phase extraction instrument with 12 parallel channels (Tianjin Agela Technologies Company, Tianjin, China) were used during the preparation process of the chosen swine and feed samples.

\subsection{Synthesis of RAC Imprinted Material}

The RAC imprinted material used in this study was synthesized in the Key laboratory of Food and Safety, Tianjin University of Science and Technology (Tianjin, China). The template RAC has active phenolic hydroxyl groups and APTES is a basic functional monomer. The $\mathrm{N}$ on the amino of APTES can combine with the $\mathrm{H}^{+}$on phenol hydroxyl group of RAC to form the functional silane precursor, and further form the polymer with the cross-linker TEOS. Hydrochloric acid is a strong acid. RAC can be replaced from the polymer and removed by methanol extraction, leaving selective cavies with recognition sites in the polymer (Figure 2). The used RAC imprinted material was verified to have good adsorption capability towards the template RAC (adsorption capacity at an RAC concentration of $120 \mathrm{mg} \mathrm{L}^{-1}: 1.99 \mathrm{mg} \mathrm{g}^{-1}$ ) [12].

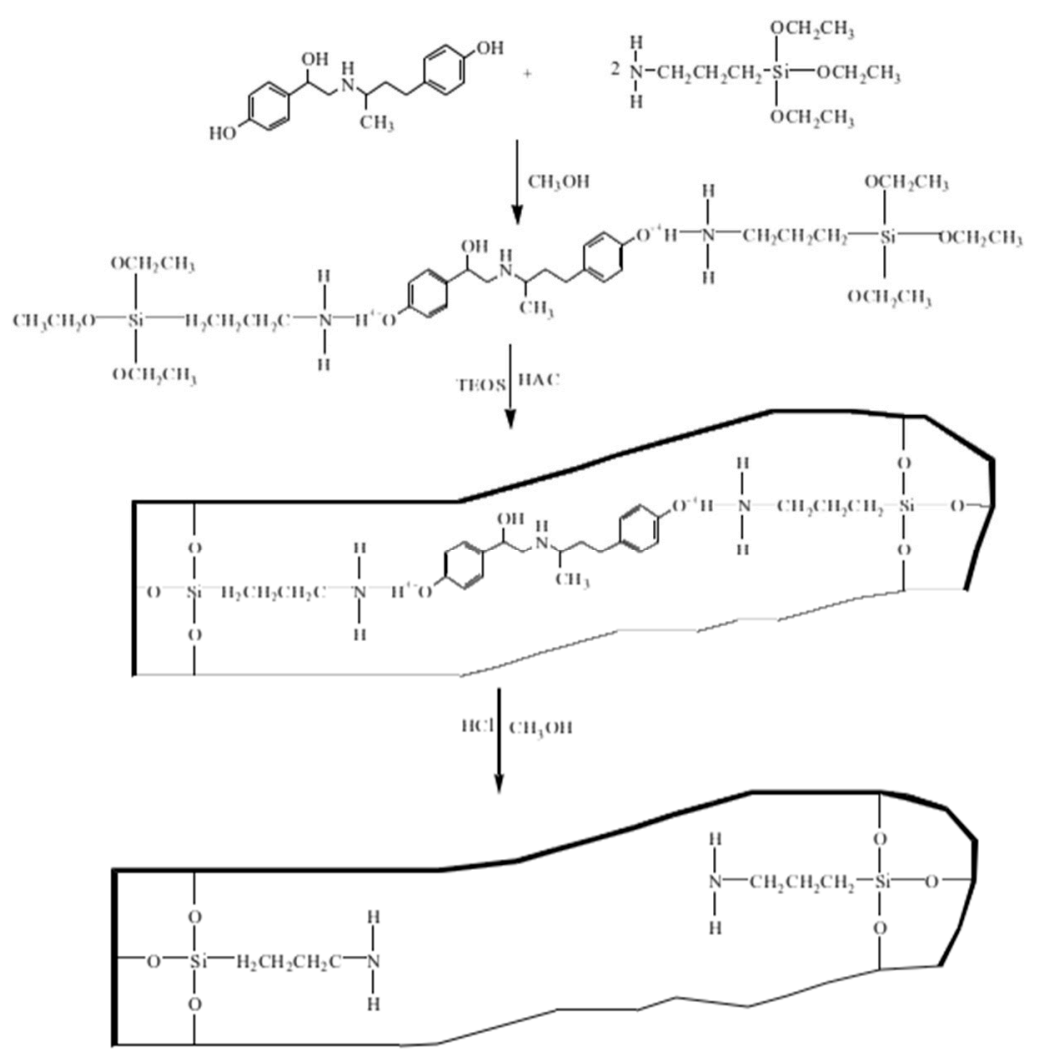

Figure 2. Schematic representation of the synthesis of RAC molecularly imprinted polymer.

Briefly, the synthetic procedure was as follows: accurately weighed RAC $(0.5 \mathrm{~g})$ was first dissolved into porogen solvent methanol $(3.0 \mathrm{~mL})$ at $40^{\circ} \mathrm{C}$ in a glassy tube. The functional monomer (APTES, 
$1.70 \mathrm{~mL}$ ) was then added and mixed uniformly. Next, the cross-linker (TEOS, $1.65 \mathrm{~mL}$ ) was added into the tube and stirred magnetically for $20 \mathrm{~min}$. A catalyzer (HAC solution, $1.0 \mathrm{~mol} \mathrm{~L}-1,0.5 \mathrm{~mL}$ ) was added, and allowed to react for $10 \mathrm{~min}$, and subsequently incubated at $40{ }^{\circ} \mathrm{C}$ for $12 \mathrm{~h}$. The solid product was then filtered, washed with methanol, and aged at $100{ }^{\circ} \mathrm{C}$ for $10 \mathrm{~h}$. Finally, the polymer product was washed with methanol $(35 \mathrm{~mL})$ and $\mathrm{HCl}$ solution $\left(1.0 \mathrm{~mol} \mathrm{~L}^{-1}, 15 \mathrm{~mL}\right)$ to remove the template RAC. The final solid product was dried and used for further research.

\subsection{Modification of the RAC Imprinted Material on the Au Electrode Surface}

Nafion is a commonly used membrane for the immobilization of recognition element in the construction of sensor, through which small ions or molecule can be easily transported. In the research, the Nafion solution was applied for RAC-MIP immobilization on the chip surface. Accurately weighed RAC imprinted material (5.0 mg) was mixed with $100 \mu \mathrm{L}$ Nafion solution (0.5 wt \%) diluted with ethanol in a glass tube. The mixture was then ultrasonically treated to form a homogeneous suspension. The degassing mixture was carefully transferred onto the surface of a QCM Au chip (9 M Hz, AT-cut, $3000 \AA, 0.196 \mathrm{~cm}^{2}$ ) fixed in the flowing cell. Finally, the mixture was air-dried in a fume hood, and the whole device was preserved under dry conditions prior to use.

\subsection{Measurement Procedure for RAC}

A series of RAC standard working solutions in the concentrations range $0.5-50.0 \mathrm{mg} \mathrm{L}^{-1}$ was prepared. These were then pumped into the flowing cell at a steady rate of $0.1 \mathrm{~mL} \mathrm{~min}^{-1}$ to allow the imprinted polymer binding of the RAC analyte. When the frequency response was stable, a large amount of deionized water was pumped to rinse the MIP-modified chip surface to remove the unbound analyte and attain a constant frequency. The piezoelectric chip was then air-dried in a fume hood and its frequency shift $(\Delta f, \mathrm{~Hz})$ before and after RAC adsorption calculated. Furthermore, an $\mathrm{HCl}$ solution $\left(0.1 \mathrm{~mol} \mathrm{~L}^{-1}\right)$ was applied into the flowing cell to desorb the RAC from the imprinted polymer layer on the chip surface. When the frequency response restored to the initial value, deionized water was employed to remove the $\mathrm{HCl}$ and the chip was then used for the subsequent RAC analyses. Each measurement procedure can be finished in $8 \mathrm{~min}$. At least three measurements were recorded for each tested RAC concentration. The average $\Delta f$ value was then used to calculate the change in mass $(\Delta m)$ on the MIP-modified piezoelectric chip according to the Sauerbrey equation. This was equivalent to the amount of RAC bound to the MIP material.

$$
\Delta f=\frac{-2 f_{0}^{2} \Delta m}{A\left(\rho_{\mathrm{q}} \mu_{\mathrm{q}}\right)^{1 / 2}}
$$

where $\Delta f$ is the frequency shift, $\mathrm{Hz} ; f_{0}$ is the resonant frequency of the quartz crystal, $\mathrm{MHz} \Delta m$ is the mass change, $\mathrm{g} ; \rho_{\mathrm{q}}$ is the density of quartz $\left(2.65 \mathrm{~g} \mathrm{~cm}^{-3}\right), \mu_{\mathrm{q}}$ is the shear modulus $\left(2.95 \times 10^{11} \mathrm{~g} \mathrm{~cm}^{-1} \mathrm{~s}^{-2}\right)$ and $A$ is the piezoelectrically active crystal area $\left(0.196 \mathrm{~cm}^{2}\right)$.

\subsection{Sample Pretreatment and Spiking Method}

Swine and feed product samples purchased from a local supermarket were employed to evaluate the potential of the constructed MIP piezoelectric sensor for application as a detector of RAC in food samples. The swine or feed product was accurately weighed $(1.0 \mathrm{~g})$ into a glassy tube, and mixed with acetonitrile $(10.0 \mathrm{~mL})$ to extract the target analyte and remove any biological impurities. After homogeneous mixing with an oscillator for $5 \mathrm{~min}$, the mixture was centrifuged for $10 \mathrm{~min}$ to separate the supernatant. The residue was extracted repeatedly with the same method, and both parts of the supernatant were combined, ultrafiltered $(0.22 \mu \mathrm{m})$ and dried under $\mathrm{N}_{2}$. The product was redissolved in methanol for further research.

To validate the accuracy and precision of the developed MIP piezoelectric sensor for RAC analysis in biological samples, the swine and feed products (1.0 g) were spiked at three levels: 10, 20 and $40 \mathrm{ng}$ 
RAC, respectively. After treatment using the same procedure, the resulting solution was applied to RAC content analysis using the MIP piezoelectric sensor and HPLC-MS/MS method.

\section{Results and Discussion}

\subsection{Surface Morphology of the MIP Piezoelectric Sensor}

Scanning electron microscopy (SEM) and atomic force microscope (AFM) were employed to characterize the surface morphology of the developed MIP piezoelectric sensor. The RAC imprinted material covered the chip surface uniformly, and exhibited a porous structure (Figure 3a,b), allowing the recognition sites formed in the cross-linking system to easily bind to the analyte. This result also demonstrated that the Nafion solution could effectively immobilize the MIP material but did not affect its binding properties to the template RAC. From the AFM image (Figure S1A), the thickness of MIP on chip surface was evaluated to be approximate $0.95 \mu \mathrm{m}$, and Figure S1B had shown the AFM image of non-edge region of the MIP modified chip surface, from which it can be seen that the MIP is uniformly attached to the chip surface.

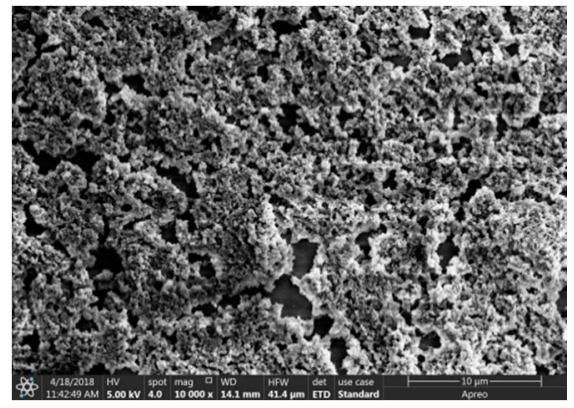

(a)

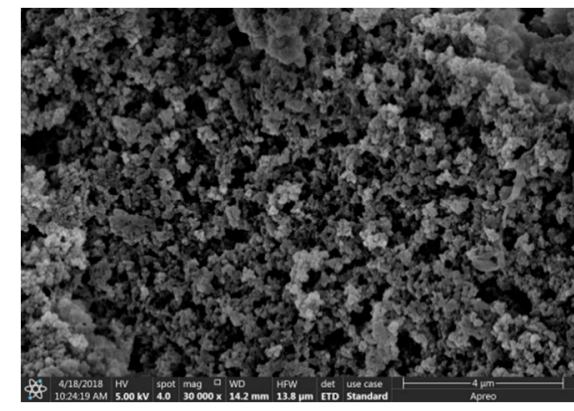

(b)

Figure 3. The SEM images of the piezoelectric chip surface modified by RAC imprinted material (a) $\times 10,000$; (b) $\times 30,000$ magnification.

\subsection{Optimization of the Amount of RAC Imprinted Material}

In the study, RAC imprinted material was synthesized and used as the recognition element of the piezoelectric sensor for specific binding to RAC. The amount of material modified on the piezoelectric chip surface directly affected the frequency response of the QCM. Thus, the binding amount of RAC was evaluated in detail. Different amounts of RAC imprinted materials (3.0, 4.0, 5.0, 6.0 and 7.0 mg) were individually dispersed in equal volume of Nafion solution $(100 \mu \mathrm{L})$, and further modified onto piezoelectric chip surface. The frequency response for each sample was then tested under the same experimental conditions.

Figure 4 illustrates that at the same tested RAC concentration, an increase in the imprinted material modified on the chip surface produced a larger frequency response and therefore, more RAC was adsorbed onto the chip surface. Thus, an increase in the tested RAC concentrations $\left(0.5-50.0 \mathrm{mg} \mathrm{L}^{-1}\right)$ produced a regular increase in the monitoring frequency response in all tested MIP amounts. When 3.0 and $4.0 \mathrm{mg}$ of imprinted material was applied to the Nafion solution $(100 \mu \mathrm{L})$, a narrow $\Delta f$ range (1.8-114.3 Hz and $2.3-164.6 \mathrm{~Hz}$, respectively) of the piezoelectric chip towards the tested RAC concentrations was achieved. The $\Delta f$ values exhibited wider ranges $(3.4-239.9 \mathrm{~Hz}, 3.5-258.3 \mathrm{~Hz}$, and $3.5-267.6 \mathrm{~Hz}$, respectively) when the amount of RAC imprinted material was increased to 5.0, 6.0 and $7.0 \mathrm{mg}$, indicating an improvement in the accuracy and precision of the detection process. Additionally, when 6.0 and $7.0 \mathrm{mg}$ of RAC-MIP was added to the Nafion solution $(100 \mu \mathrm{L})$, the formed membrane appeared to crack and shed off from the chip surface, leading to poor stability and reusability of the developed piezoelectric chip. Based on the above results, $5.0 \mathrm{mg}$ of RAC imprinted material 
in $100 \mu \mathrm{L}$ of Nafion solution was established as the optimal amount for MIP modification of the piezoelectric chip.

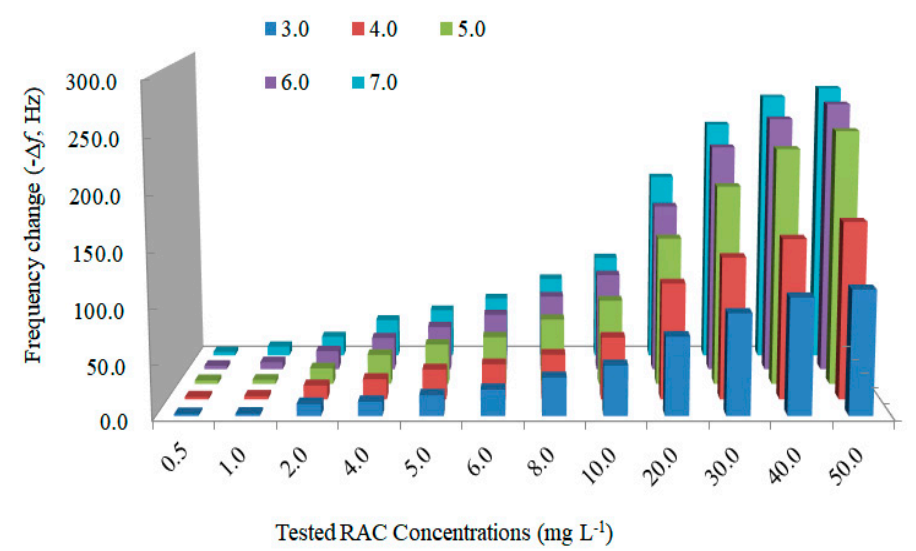

Figure 4. Comparison of the frequency response of the developed piezoelectric chip using different amounts of RAC imprinted material at the concentration range of $0.5-50.0 \mathrm{mg} \mathrm{L}^{-1}$.

\subsection{Response of the Developed Piezoelectric Chip to RAC}

Standard working solutions at a series of RAC concentrations $\left(0.5-50.0 \mathrm{mg} \mathrm{L}^{-1}\right)$ were individually pumped into a flowing cell in which the RAC-MIP modified piezoelectric chip was first fixed. At least three parallel analyses were conducted for each RAC concentration to establish an average $\Delta f$ value.

Figure 5a reveals that with the increase in the tested RAC concentrations resulted in an increase in the $\Delta f$ value of the piezoelectric chip, signifying that more RAC was bound by the immobilized imprinted material on the chip surface. Good linearity between the $\Delta f$ value and RAC concentration was observed at the concentration range $0.5-20.0 \mathrm{mg} \mathrm{L}^{-1}$ with $\mathrm{R}^{2}=0.9845$, demonstrating that the system could be applied to the quantitative analysis of RAC. The results revealed limits of detection $\left(\mathrm{LOD}, S / N=3\right.$ ) and quantification $(\mathrm{LOQ}, S / N=10)$ for RAC in 0.042 and $0.14 \mathrm{mg} \mathrm{L}^{-1}$ standard working solutions, respectively.

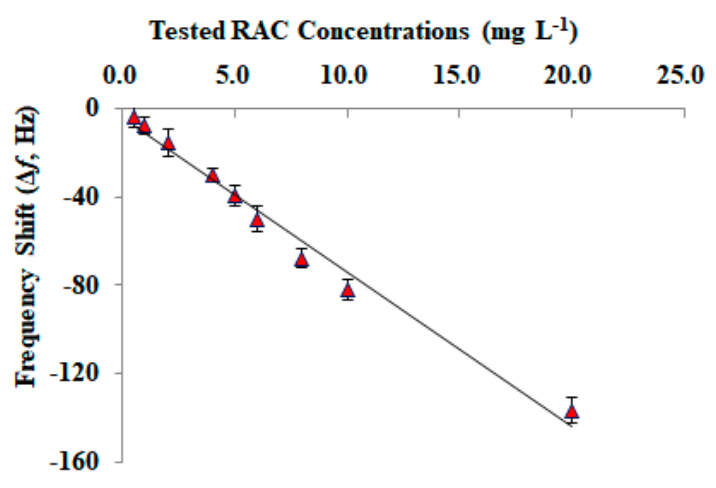

(a)

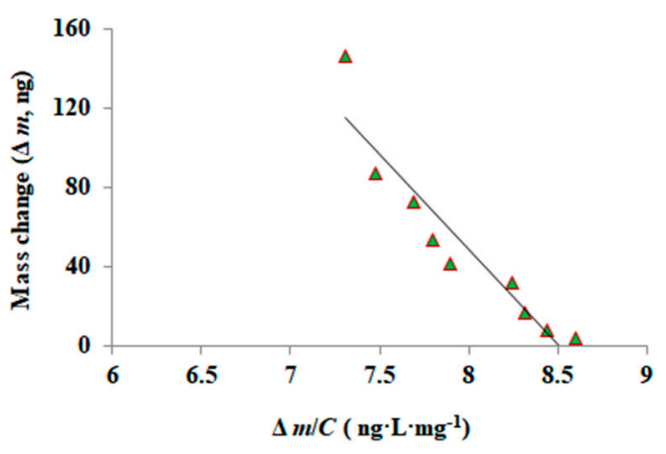

(b)

Figure 5. Linear curves of the frequency shift value $(\Delta f)$ for the tested RAC concentrations (a) and Langmuir analysis (b).

Further, the $\Delta m$ value on the surface of the molecularly imprinted piezoelectric chip at each tested RAC concentration was calculated according to the $\Delta f$ value. The results were then used to calculate 
the equilibrium parameters, such as the association constant $\left(K_{\mathrm{a}}\right)$ and maximum saturation binding value $\left(\Delta m_{\max }\right)$ from the Langmuir adsorption isotherm.

$$
\Delta m=\frac{\Delta m_{\max } \times K_{\mathrm{a}} \times C}{1+K_{\mathrm{a}} \times C}
$$

After rearranging the equation, the relationship was attained by plotting $\Delta m$ versus $\Delta m / C$, with slope $1 / K_{\mathrm{a}}$ and $\mathrm{Y}$-intercept $\Delta m_{\max }$, as follows:

$$
\Delta m=-\frac{1}{K_{\mathrm{a}}} \times \frac{\Delta m}{\mathrm{C}}+\Delta m_{\max }
$$

Thus, $\Delta m_{\max }$ and $K_{\mathrm{a}}$ were calculated from the plotted data (Figure $5 \mathrm{~b}$ ) as $816.1 \mathrm{ng}$ and $0.0104 \mathrm{mg}^{-1} \mathrm{~L}$, respectively, revealing that the synthesized imprinted material displayed a strong affinity toward the RAC analyte.

The selectivity of the developed MIP piezoelectric chip was evaluated using three RAC structural analogues, isoproterenol, terbutaline, and isoxsuprine in the concentration range $0.5-20.0 \mathrm{mg} \mathrm{L}^{-1}$ (Figure S2). Notably, out of all the tested analogous, the RAC system afforded the largest $\Delta f$ values under all the tested concentrations. This was attributed to the better affinity of the imprinted material to the template RAC over that of the other analytes. When the concentration of each analyte was $10.0 \mathrm{mg} \mathrm{L}^{-1}$, the selectivity coefficient $\left(\Delta f_{\mathrm{RAC}} / \Delta f_{\text {analogue }}\right)$ for isoproterenol, terbutaline, and isoxsuprine was calculated as 1.96, 1.39 and 1.61, respectively. These results verified that the RAC imprinted material, applied as the recognition element of the piezoelectric sensor, still displayed good selective ability towards the template. The relatively weak $\Delta f$ value of the analogues is mainly attributed to their similar structure to RAC.

\subsection{Regeneration of the Developed Piezoelectric Chip}

The regeneration process requires the complete removal of RAC from the cavities of the imprinted material. Simultaneously, the polymer layer on the surface of the chip must not be damaged so as not to affect the next determination process. Thus, the conditions for chip regeneration directly affected the accuracy, reproducibility, sensitivity, and lifetime of the developed MIP piezoelectric chip. Based on the previous experiment, a series of solutions with different properties including methanol, water, $\mathrm{NH}_{3} \cdot \mathrm{H}_{2} \mathrm{O}\left(0.1\right.$ and $\left.0.5 \mathrm{~mol} \mathrm{~L}^{-1}\right), \mathrm{HCl}\left(0.1\right.$ and $\left.0.5 \mathrm{~mol} \mathrm{~L}^{-1}\right)$, ammonium methanol (containing $5 \%$ $\mathrm{NH}_{3} \cdot \mathrm{H}_{2} \mathrm{O}$ ), and acidified methanol (containing $5 \% \mathrm{HCl}$ ) were tested for chip regeneration (Figure 6).

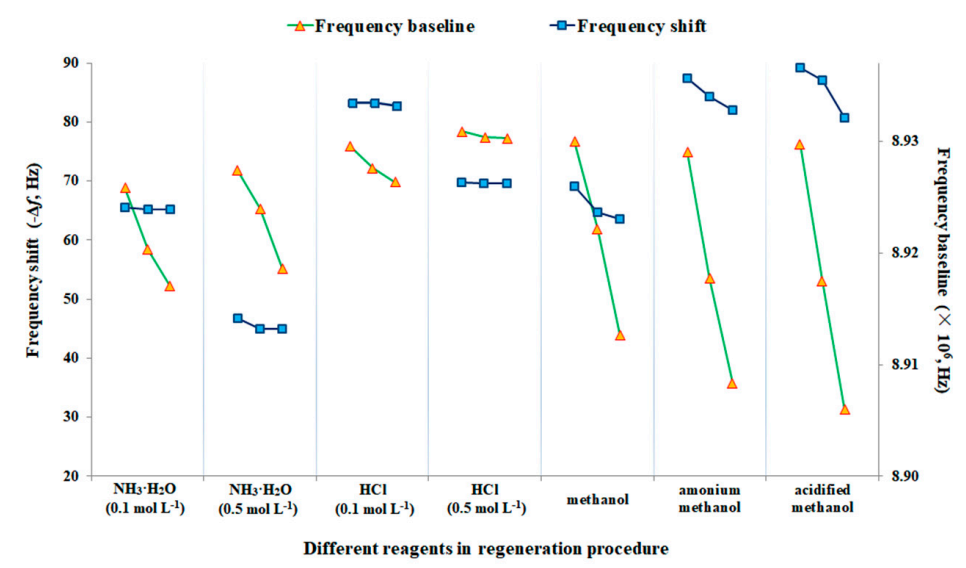

Figure 6. Comparison of the results in the regeneration procedure using different regeneration solutions.

No change in the frequency response of the piezoelectric chip (not shown in Figure 6) was observed when pure water was applied for RAC desorption from the MIP material. This suggests 
that pure water is not effective for RAC removal from the imprinted material. On the other hand, significant frequency shifts were observed when the regeneration solution was acidic or alkaline $(\mathrm{HCl}$ and $\mathrm{NH}_{3} \cdot \mathrm{H}_{2} \mathrm{O}$, respectively). This occurred because the binding of the imprinted material to RAC is based on the interaction of an acid-base proton pair. Moreover, when the regeneration solution contained methanol, the value of the baseline frequency grew rapidly, signifying that the immobilized MIP layer on the piezoelectric chip surface was damaged, thereby affecting the next analytical process. This was attributed to the dissolution of methanol in the Nafion film causing the MIP material to fall off the surface of the chip. The frequency response returned to the original value when $\mathrm{HCl}$ and $\mathrm{NH}_{3} \cdot \mathrm{H}_{2} \mathrm{O}$ solutions were employed. After three consecutive injection/analysis/recovery processes of an identical RAC solution, the $\mathrm{HCl}$ solution $\left(0.5 \mathrm{~mol} \mathrm{~L}^{-1}\right)$ displayed a lower frequency decline $(95.1 \mathrm{~Hz})$ than the other regeneration solutions $\left(0.1 \mathrm{~mol} \mathrm{~L}^{-1} \mathrm{HCl}: 292.7 \mathrm{~Hz} ; 0.1 \mathrm{~mol} \mathrm{~L}^{-1} \mathrm{NH}_{3} \cdot \mathrm{H}_{2} \mathrm{O}\right.$ : $174.6 \mathrm{~Hz} ; 0.5 \mathrm{~mol} \mathrm{~L}^{-1} \mathrm{NH}_{3} \cdot \mathrm{H}_{2} \mathrm{O}: 965.0 \mathrm{~Hz}$ ), indicating less damage from the regeneration solution to the immobilized MIP layer on the chip surface. Thus, the $0.5 \mathrm{~mol} \mathrm{~L}^{-1} \mathrm{HCl}$ solution was selected for chip regeneration. A single MIP piezoelectric chip could be reused 30 times with a frequency response of $86.5 \%$. After being stored in air for one month, the MIP piezoelectric chip exhibited a frequency response of $94.3 \%$, verifying that the proposed MIP piezoelectric chip displays remarkable reusability and stability for RAC analysis.

\subsection{Sample Matrix Effect and Recovery Study}

Biological impurities, such as proteins and lipids in the swine and feed samples might lead to non-specific adsorption on the MIP modified piezoelectric chip, affecting the accuracy and precision of RAC analysis. In this study, the matrix effect from the selected samples to be removed was evaluated in detail to ensure the accuracy and precision of the developed MIP piezoelectric sensor in RAC analysis.

The matrix standard curves under a series of RAC concentrations $\left(2.5-100.0 \mu \mathrm{g} \mathrm{kg}^{-1}\right)$ in the swine and feed samples are presented in Figure S3. Good linearity $\left(R^{2} \geq 0.99\right)$ was achieved for the two chosen samples with LOD values $(\mathrm{S} / \mathrm{N}=3)$ of $0.46 \mathrm{ng} \mathrm{g}^{-1}$ (swine) and $0.38 \mathrm{ng} \mathrm{g}^{-1}$ (feed). In the spiked and recovery studies, good recoveries at three spiked levels (10.0, 20.0 and $40.0 \mathrm{ng} \mathrm{g}^{-1}$ ) were in the ranges of $75.9-92.1 \%$ (swine) and $84.3-93.3 \%$ (feed) with acceptable precision values (RSD, $\mathrm{n}=3$ ) of $2.3-6.4 \%$ (swine) and $3.2-4.1 \%$ (feed), respectively (Table 1). The typical HPLC-MS/MS method was also employed for RAC analysis in the spiked samples at each level with recovery results of $78.9-93.0 \%$ and an RSD $(n=3)$ range of $1.8-4.2 \%$. The regression equation for the recovery data from the developed MIP piezoelectric chip and HPLC-MS/MS method was Y $=0.8388 \mathrm{X}+12.996$ with a correlation coefficient of 0.9611 , demonstrating that the developed MIP piezoelectric chip can be applied to accurately detect RAC in swine and feed samples. Table 2 showed the merits of MIP piezoelectric chip for RAC analysis in various samples compared with other methods, indicating the developed MIP piezoelectric chip offered a sensitive, cost-effective and portable method for RAC analysis in complex samples.

Table 1. Recoveries of RAC in spiked swine and feed samples using the MIP piezoelectric chip and HPLC-MS/MS.

\begin{tabular}{cccccc}
\hline \multirow{2}{*}{ Sample } & $\begin{array}{c}\text { Spiked Levels } \\
\text { (ng g }^{-\mathbf{1}} \text { ) }\end{array}$ & \multicolumn{2}{c}{$\begin{array}{c}\text { The Developed MIP } \\
\text { Piezoelectric Chip }\end{array}$} & \multicolumn{2}{c}{ HPLC-MS/MS } \\
\cline { 3 - 6 } & & Recovery (\%) & $\begin{array}{c}\text { RSD } \\
(\mathbf{\%}, \boldsymbol{n}=\mathbf{3})\end{array}$ & Recovery (\%) & $\begin{array}{c}\text { RSD } \\
(\mathbf{\%}, \boldsymbol{n}=\mathbf{3})\end{array}$ \\
\hline \multirow{3}{*}{ Swine } & 10.0 & 75.9 & 6.4 & 78.9 & 4.2 \\
& 20.0 & 85.6 & 4.4 & 84.9 & 2.7 \\
& 40.0 & 92.1 & 2.3 & 93.0 & 2.4 \\
\hline \multirow{3}{*}{ Feed } & 10.0 & 84.3 & 4.1 & 86.7 & 3.7 \\
& 20.0 & 88.4 & 3.8 & 89.2 & 2.6 \\
& 40.0 & 93.3 & 3.2 & 92.9 & 1.8 \\
\hline
\end{tabular}


Table 2. Comparison of different methods for RAC determination in various samples.

\begin{tabular}{|c|c|c|c|c|c|}
\hline Methods & Linear Range & LOD & Required Time & Samples & References \\
\hline MIP-SPE HPLC & $0.04-18 \mu \mathrm{g} \mathrm{L}^{-1}$ & $4.6 \mathrm{ng} \mathrm{L}^{-1}$ & $>30 \mathrm{~min}$ & Swine & {$[12]$} \\
\hline $\begin{array}{c}\mathrm{Fe}_{3} \mathrm{O}_{4} @ \mathrm{MIP}-\mathrm{SPE} \\
\text { HPLC }\end{array}$ & $0.5-100.0 \mu \mathrm{g} \mathrm{kg}^{-1}$ & $0.05 \mu \mathrm{g} \mathrm{kg}^{-1}$ & $>50 \mathrm{~min}$ & Swine & [13] \\
\hline LC-MS/MS & $\begin{array}{c}- \\
0-100.0 \mu \mathrm{g} \mathrm{kg}^{-1} \\
2.5-20 \mu \mathrm{g} \mathrm{kg}^{-1}\end{array}$ & $\begin{array}{c}1.0 \mu \mathrm{g} \mathrm{kg}^{-1} \\
1.91 \mu \mathrm{g} \mathrm{kg}^{-1} \\
1.5 \mu \mathrm{g} \mathrm{kg}^{-1}\end{array}$ & $\begin{array}{l}>30 \mathrm{~min} \\
>60 \mathrm{~min} \\
4.5 \mathrm{~min}\end{array}$ & $\begin{array}{l}\text { Bovine muscle } \\
\text { Meat, bone meal } \\
\text { Swine }\end{array}$ & $\begin{array}{l}{[14]} \\
{[16]} \\
{[17]}\end{array}$ \\
\hline $\begin{array}{l}\text { Fluorescence } \\
\text { immunoassay }\end{array}$ & $2.3-50 \mu \mathrm{g} \mathrm{L}^{-1}$ & $1.0 \mu \mathrm{g} \mathrm{L}^{-1}$ & $10 \mathrm{~min}$ & Turkey meat & [18] \\
\hline $\begin{array}{l}\text { Electrochemical } \\
\text { immunosensor }\end{array}$ & $\begin{array}{c}0.01-5 \mu \mathrm{g} \cdot \mathrm{mL}^{-1} \\
1-40 \mu \mathrm{g} \mathrm{L} \mathrm{L}^{-1}\end{array}$ & $\begin{array}{c}2.3 \mathrm{ng} \mathrm{L}^{-1} \\
0.34 \mathrm{gg} \mathrm{L}^{-1}\end{array}$ & $\begin{array}{l}>\mathrm{h} \\
-\end{array}$ & $\begin{array}{l}\text { Swine urine } \\
\text { Swine muscle }\end{array}$ & $\begin{array}{l}{[19]} \\
{[21]}\end{array}$ \\
\hline $\begin{array}{l}\text { Electrochemical } \\
\text { aptasensor }\end{array}$ & $10^{-12}-10^{-8} \mathrm{~mol} \mathrm{~L}^{-1}$ & $5.0 \times 10^{-13} \mathrm{~mol} \mathrm{~L}^{-1}$ & $>35 \mathrm{~min}$ & Swine urine & [20] \\
\hline
\end{tabular}

\section{Conclusions}

A reproducible molecularly imprinted piezoelectric sensor that allows for the accurate, sensitive and quantitative detection of RAC in swine and feed samples has been successfully developed. The synthesized RAC imprinted material, which is directly immobilized on the piezoelectric chip as the recognition element, exhibits remarkable binding affinity to the target RAC. The developed piezoelectric sensing chip is portable, can be reused for at least 30 times and easily stored for a long time, suggesting its potential value in the on-site, reproducible, and realize low-cost determination of contaminants in food products. This research has promoted further integration of molecular imprinting and piezoelectric sensing techniques, and expanded their application to the development of new strategies and devices in the field of food safety.

Supplementary Materials: The following are available online at http:/ /www.mdpi.com/1424-8220/18/6/1870/ s1, Figure S1: AFM image of the edge (A) and non-edge (B) region of RAC-MIP modified chip, Figure S2: Response of the developed MIP piezoelectric chip to RAC and its structural analogues, Figure S3: The matrix standard curves under the RAC concentrations of $2.5-100.0 \mu \mathrm{g} \mathrm{kg}^{-1}$ in the swine and feed products.

Author Contributions: M.P. conceived and designed the experiments as the first author. R.L. performed the experiments as the second author. L.X. performed the experiments as the third author. J.Y. analyzed the data as the fourth author. X.C. performed the experiments as the fifth author and. S.W. conceived and designed the experiments as the corresponding author.

Funding: This research was funded by Key Project of Tianjin Education Commission Scientific Research Plan (No. 2017ZD01).

Conflicts of Interest: All the authors have declared no conflict of interest.

\section{References}

1. Bergen, W.; Johnson, S.; Skjaerlund, D.; Babiker, A.; Ames, N.; Merkel, R.; Anderson, D. Muscle protein metabolism in finishing pigs fed ractopamine. J. Anim. Sci. 1989, 67, 2255-2262. [CrossRef] [PubMed]

2. Cheng, T.; Shelver, W.; Hong, C.; Mccann, S.; Davis, W.; Zhang, Y.; Ambrosone, C.; Smith, D. Urinary excretion of the $\beta$-adrenergic feed additives ractopamine and zilpaterol in breast and lung cancer patients. J. Agric. Food Chem. 2016, 64, 7632-7639. [CrossRef] [PubMed]

3. Van Wettere, W.; Pain, S.; Hughes, P. Dietary ractopamine supplementation during the first lactation affects milk composition, piglet growth and sow reproductive performance. Anim. Reprod. Sci. 2016, 174, 87-92. [CrossRef] [PubMed]

4. Huang, L.; Shi, J.; Pan, Y.; Wang, L.; Chen, D.; Xie, S.; Liu, Z.; Yuan, Z. Elimination and concentration correlations between edible tissues and biological fluids and hair of ractopamine in pigs and goats fed with ractopamine-medicated feed. J. Agric. Food Chem. 2016, 64, 2012-2020. [CrossRef] [PubMed] 
5. Marcolla, C.; Holanda, D.; Ferreira, S.; Rocha, G.; Nvl, S.; Duarte, M.; Abreu, M.; Saraiva, A. Chromium, CLA, and ractopamine for finishing pigs. J. Anim. Sci. 2017, 95, 4472-4480. [CrossRef] [PubMed]

6. Barbosa, E.; Bridi, A.; Novais, A.; Santos, R.; Frederico, G.; Alves, J.; Barata, C.; Santos, E.; Caio, A. Use of ractopamine during compensatory gain of finishing pigs on carcass and meat performance and quality. Arq. Bras. Med. Vet. Zootec. 2017, 69, 1660-1668. [CrossRef]

7. Blanca, J.; Muñoz, P.; Morgado, M.; Méndez, N.; Aranda, A.; Reuvers, T.; Hooghuis, H. Determination of clenbuterol, ractopamine and zilpaterol in liver and urine by liquid chromatography tandem mass spectrometry. Anal. Chim. Acta 2005, 529, 199-205. [CrossRef]

8. Armstrong, T.; Vers, D.; Wagner, J.; Anderson, D.; Weldon, W.; Berg, E. The effect of dietary ractopamine concentration and duration of feeding on growth performance, carcass characteristics, and meat quality of finishing pigs. J. Anim. Sci. 2004, 82, 3245-3253. [CrossRef] [PubMed]

9. Noel, J.; Barstow, T.; Broxterman, R.; Mccoy, G.; Phelps, K.; Gonzalez, J. Effect of Ractopamine-HCL on muscle fiber types and finishing barrow exhaustion. Meat Sci. 2016, 112, 110. [CrossRef]

10. The Ministry of Agriculture. Regulation NO. 193; The Ministry of Agriculture: Beijing, China, 2002.

11. Niño, A.; Granja, R.; Wanschel, A.; Salerno, A. The challenges of ractopamine use in meat production for export to European Union and Russia. Food Control 2015, 72. [CrossRef]

12. Wang, S.; Liu, L.; Fang, G.; Zhang, C.; He, J. Molecularly imprinted polymer for the determination of trace ractopamine in pork using SPE followed by HPLC with fluorescence detection. J. Sep. Sci. 2009, 32, 1333-1339. [CrossRef] [PubMed]

13. Tang, Y.; Gao, J.; Liu, X.; Lan, J.; Gao, X.; Ma, Y.; Li, M.; Li, J. Determination of ractopamine in pork using a magnetic molecularly imprinted polymer as adsorbent followed by HPLC. Food Chem. 2016, 201, 72-79. [CrossRef] [PubMed]

14. Koostra, P.; Kuijpers, C.; Wubs, K.; van Doorn, D.; Sterk, S.; van Ginkel, L.; Stephany, R. The analysis of beta-agonists in bovine muscle using molecular imprinted polymers with ion trap LCMS screening. Anal. Chim. Acta 2005, 529, 75-81. [CrossRef]

15. He, L.; Su, Y.; Zeng, Z.; Liu, Y.; Huang, X. Determination of ractopamine and clenbuterol in feeds by gas chromatography-mass spectrometry. Anim. Feed Sci. Tech. 2007, 132, 316-323. [CrossRef]

16. Gressler, V.; Franzen, A.; de Lima, G.; Tavernari, F.; Dalla Costa, O.; Feddern, V. Development of a readily applied method to quantify ractopamine residue in meat and bone meal by QuEchERS-LC-MS/MS. J. Chromatogr. B 2016, 1015-1016, 192-200. [CrossRef] [PubMed]

17. Valese, A.; Oliveira, G.; Kleemann, C.; Molognoni, L.; Daguer, H. A QuEChERS/LC-MS method for the analysis of ractopamine in pork. J. Food Compos. Anal. 2016, 47, 38-44. [CrossRef]

18. Zvereva, E.; Shpakova, N.; Zherdev, A.; Liu, L.; Xu, C.; Eremin, S.; Dzantiev, B. Fluorescence polarization immunoassay of ractopamine. Appl. Biochem. Microbiol. 2016, 52, 673-678. [CrossRef]

19. He, L.; Guo, C.; Song, Y.; Zhang, S.; Wang, M.; Peng, D.; Fang, S.; Zhang, Z.; Liu, C. Chitosan stabilized gold nanoparticle based electrochemical ractopamine immunoassay. Microchim. Acta 2017, 184, 2919-2924. [CrossRef]

20. Yang, F.; Wang, P.; Wang, R.; Zhou, Y.; Su, X.; He, Y.; Shi, L.; Yao, D. Label free electrochemical aptasensor for ultrasensitive detection of ractopamine. Biosens. Bioelectron. 2016, 77, 347-352. [CrossRef] [PubMed]

21. Chen, S.; Zhang, J.; Gan, N.; Hu, F.; Li, T.; Cao, Y.; Pan, D. An on-site immunosensor for ractopamine based on a personal glucose meter and using magnetic beta-cyclodextrin-coated nanoparticles for enrichment, and an invertase-labeled nanogold probe for signal amplification. Microchim. Acta 2015, 182, 815-822. [CrossRef]

22. Chen, D.; Yang, M.; Zheng, N.; Xie, N.; Liu, D.; Xie, C.; Yao, D. A novel aptasensor for electrochemical detection of ractopamine, clenbuterol, salbutamol, phenylethanolamine and procaterol. Biosens. Bioelectron. 2016, 80, 525-531. [CrossRef] [PubMed]

23. Schirhagl, R. Bioapplications for molecularly imprinted polymers. Anal. Chem. 2004, 86, 250-261. [CrossRef] [PubMed]

24. Rachkov, A.; Cheong, S.; El'Skaya, A.; Yano, K.; Karube, I. Molecularly imprinted polymers as artificial steroid receptors. Polym. Adv. Technol. 1998, 9, 511-519. [CrossRef]

25. Montes, N.; Granja, R.; Reche, K.; Giannotti, F.; de Souza, J.; Ferrari, S.; Dos Santos, A.; Wanschel, A.; Salerno, A. Laboratory validation of an LC-MS/MS method for the detection of ractopamine, clenbuterol and salbutamol in bovine and swine muscle at sub- $\mu \mathrm{g} / \mathrm{kg}$ regulatory limits. Food Addit. Contam. A. 2017, 34, 785-792. [CrossRef] 
26. And, U.; Peppas, N. Structural analysis and diffusional behavior of molecularly imprinted polymer networks for cholesterol recognition. Chem. Mater. 2015, 17, 6719-6727. [CrossRef]

27. Wulff, G. Enzyme-like catalysis by molecularly imprinted polymers. Chem. Rev. 2002, 102, 1-27. [CrossRef] [PubMed]

28. He, C.; Long, Y.; Pan, J.; Li, K.; Liu, F. Application of molecularly imprinted polymers to solid-phase extraction of analytes from real samples. J. Biochem. Biophys. Methods 2007, 70, 133-150. [CrossRef] [PubMed]

29. Haupt, K.; Mosbach, K. Molecularly imprinted polymers and their use in biomimetic sensors. Chem. Rev. 2000, 100, 2495-2504. [CrossRef] [PubMed]

30. Piletsky, S.; Turner, A. Electrochemical sensors based on molecularly imprinted polymers. TrAC Trends Anal. Chem. 2004, 23, 36-48. [CrossRef]

31. Wackerlig, J.; Schirhagl, R. Applications of molecularly imprinted polymer nanoparticles and their advances toward industrial use: A review. Anal. Chem. 2016, 88, 250-261. [CrossRef] [PubMed]

32. Emir, D.; Keçili, R.; Ersöz, A.; Say, R. Molecular imprinting technology in quartz crystal microbalance (QCM) sensors. Sensors 2017, 17, 454. [CrossRef] [PubMed]

33. Lach, P.; Sharma, P.; Golebiewska, K.; Cieplak, M.; D'Souza, F.; Kutner, W. Molecularly imprinted polymer chemosensor for selective determination of an N-Nitroso-l-proline food toxin. Chem.-Eur. J. 2017, 23, 1942-1949. [CrossRef] [PubMed]

34. Singh, A.; Singh, M. Electrochemical and piezoelectric monitoring of taurine via electropolymerized molecularly imprinted films. J. Mol. Recognit. 2017, 30. [CrossRef] [PubMed]

35. Ayankojo, A.; Reut, J.; Boroznjak, R.; Öpik, A.; Syritski, V. Molecularly imprinted poly(meta-phenylenediamine) based QCM sensor for detecting Amoxicillin. Sens. Actuators B Chem. 2018, 258, 766-774. [CrossRef]

36. Selvolini, G.; Marrazza, G. MIP-Based sensors: Promising new tools for cancer biomarker determination. Sensors 2017, 17, 718. [CrossRef] [PubMed]

37. Kugimiya, A.; Takeuchi, T. Molecularly imprinted polymer-coated quartz crystal microbalance for detection of biological hormone. Electroanalysis 2015, 11, 1158-1160. [CrossRef]

38. Battal, D.; Akgönüllü, S.; Yalcin, M.; Yavuz, H.; Denizli, A. Molecularly imprinted polymer based quartz crystal microbalance sensor system for sensitive and label-free detection of synthetic cannabinoids in urine. Biosens. Bioelectron. 2018, 111, 10-17. [CrossRef] [PubMed]

39. Yun, Y.; Pan, M.; Fang, G.; Gu, Y.; Wen, W.; Xue, R.; Wang, S. An electrodeposited molecularly imprinted quartz crystal microbalance sensor sensitized with AuNPs and rGO material for highly selective and sensitive detection of amantadine. RSC Adv. 2018, 8, 6600-6607. [CrossRef] 